\title{
Thermal Performance Evaluation of Thermoelectric Module
}

\author{
Patchara Wongpaisarnkit, Krawee Treeamnuk, Tawarat Treeamnuk
}

\begin{abstract}
This article ascribes about the thermoelectric module that conveniently creates the difference temperature between the both of its sides by supplying the electricity. The study aims to test the performance of the heat generating and heat exchanging capability of the thermoelectric module model TEC-12710 for the possibility evaluation when it will be modified in the agricultural products drying system. The experiment apparatus was prepared by install the air fin heat exchangers on the $16 \mathrm{~cm}^{2}$ of both sides of the thermoelectric module and then, enforced the air flow through the system and measured the inlet-outlet of air properties. The results found that the supplying of $16 \mathrm{~V}, 8.5 \mathrm{~A}$ DC electricity to the module gains the air temperature from $30^{\circ} \mathrm{C} 68 \% \mathrm{RH}$ to $52.3^{\circ} \mathrm{C}$ $26.8 \% \mathrm{RH}$ on the hot side of the module. The system consumes a $40 \mathrm{~W}$ of power and gives the highest moisture extraction rate (MER) at $0.016 \mathrm{~kg}_{\text {water }} / \mathrm{h}$ on the cold side of module by supplying of $6 \mathrm{~V} 3.5 \mathrm{~A}$ and it have the coefficient of performance (COP) at 1.14. It is possible to adapt this module with the drying system especially the heat pump drying system.
\end{abstract}

Keywords - thermoelectric module, moisture extraction rate, $\mathrm{COP}$

\section{Introduction}

Nowadays the air conditioning system be important for household and industry section because the usefulness of its both cooling and heating parts. Generally, air conditioning used to improve the comfort of occupants by control temperature, humidity, air distribution and air flow rate. In addition, it can be used for food preservation such as cooling in refrigerator that can kept food longer and can applied to be used to reduce the humidity and heat of air for the drying process. Drying is a one way of food preservation that be popular because dried product can keep for a long time and can be eaten as nutritious snacks else can be easy used in cooking [1]. Drying food is the process which used warm air to removed moisture from food. In usually, the sun drying is easiest way by using surrounding air that warm and dry to

Patchara Wongpaisarnkit

School of Mechanical Engineering, Institute of Engineering Suranaree University of Technology Thailand

Krawee Treeamnuk

School of Mechanical Engineering, Institute of Engineering Suranaree University of Technology Thailand

Tawarat Treeamnuk

School of Agricultural Engineering, Institute of Engineering Suranaree University of Technology

Thailand remove the moisture [2] but some tropical countries cannot do a sun drying because it need a low humidity and warm air in drying. Another way, the artificial drying is needed to solve this problem.

\section{Heat pump}

The application of heat pump system is a warm and dry air producer for food drying process. In practically, a mechanical vapor compression refrigeration (VCR) cycle was applied to pump the heat in the system. Their components are Compressor, Evaporator, Expansion valve, Condenser and the refrigerants that was used as a working fluid in system. Two components of the VCR cycle were used in heat pump system such as Compressor and Evaporator. When the refrigerant travels through evaporator, it removes the heat from evaporator and transfers to the condenser (Fig. 1).

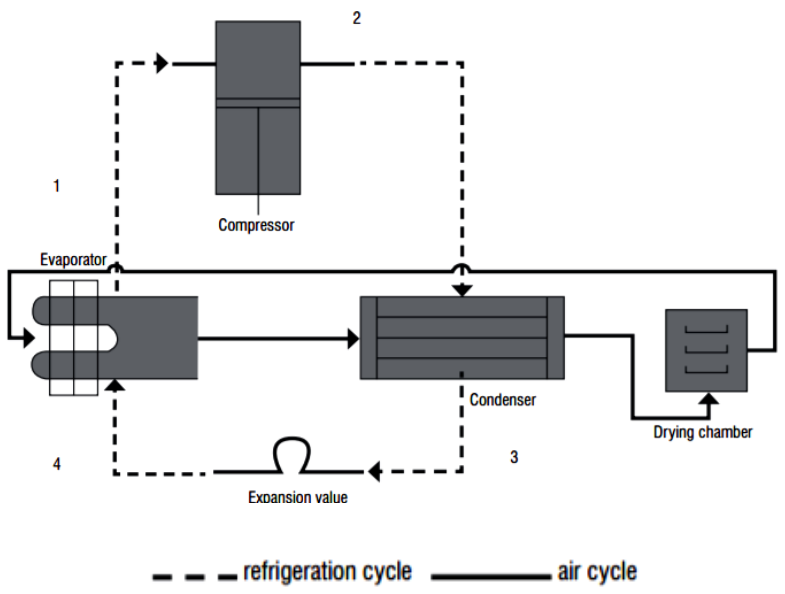

Figure 1. Heat pump VCR dryer (Closed system) [3]

From the Fig. 1 show the operation diagram of VCR closed system heat pump dryer that has two path circuits, one is air path and other is refrigerants path, both paths are separated out. The operation of the system starts by the drying air in air path was flowed by the blower. The process $1 \rightarrow 2$, air was heated up to be the drying air by condenser and it have a lower relative humidity. After that, in process $2 \rightarrow 3$ the drying air flow pass the drying chamber and lose the heat to the products while it receives the moisture from the products too. Therefore, the drying air at position (3) is high relative humidity and low temperature. Finally, in process $3 \rightarrow 4$ the humid air flow through evaporator to condense the water out and change to the dry air again. $\mathrm{M}$. Fatoh [4] has been dried the Jew's mallow by VCR opened system heat pump dryer. A new air from surround was taken into the system and discharge out after through drying chamber, the maximum productivity is $5.4 \mathrm{~kg} / \mathrm{m}^{2} \mathrm{~h}$ and minimum SEC is 3,695 kJ/ $\mathrm{kg}_{\text {water }}$. Qi-Long Shi [5] has been used VCR dryer with the electric heater assisted in closed system for the horse mackerel drying, found the VCR dryer 
Proc. of the Eighth International Conference On Advances in Mechanical, Aeronautical and Production Techniques - MAPT 2018 Copyright (C) Institute of Research Engineers and Doctors. All rights reserved.

ISBN: 978-1-63248-147-4 doi: 10.15224/ 978-1-63248-147-4-23

in closed system is good for produce intermediate moisture food. The advantage of VCR dryer in closed system by internal recirculating the drying air is the dustless and free other outside contamination. From the previous report about usefulness of heat pump dryer however, the VCR system is a complicated system and have many components in operation. In addition, the VCR cycle use a harmful substance as a working fluid and could be hazardous effects on environment if it leaked out.

\section{Thermoelectric module}

Thermoelectric module is a thin semiconductor-based electronic device. It can directly generate the heat flux on its both sides when supplied the electricity. The difference temperature between the sides of device was affect by the heat flux generated, so its behavior looks like a small heat pump. Moreover, the module that have difference temperature between the sides can also convert the heat to electricity too. Thus, the thermoelectric applications are mainly based on those two aspects by either converting heat to electricity (TEG) or converting electricity to heat (TEC) [6]. The TEC module basics operation is applying a voltage DC power to a device to activate electron, electron will be the heat carrier from one side to the other side that make one module face cooled while the opposite face is simultaneously heated as in Fig 2.

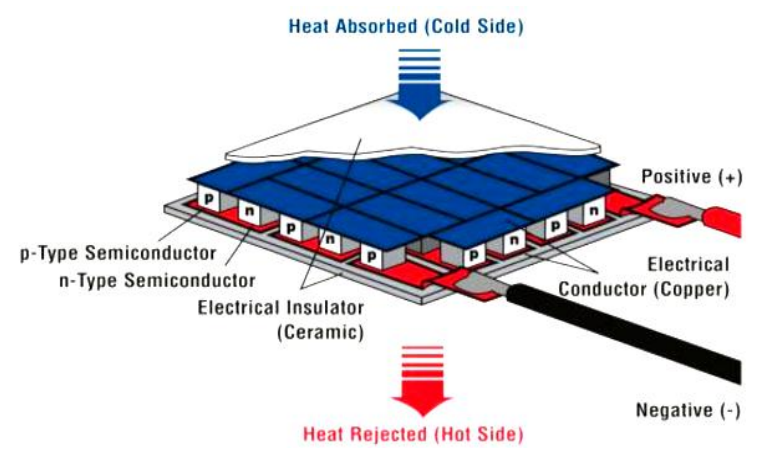

Figure 2. Thermoelectric module [7]

The thermoelectric modules popular use in air conditioning, heating and cooling system. Researchers are applying thermoelectric module in many ways. Diana Enescu [8] has been manufactured refrigerator that has a capacity of 42 liters $(42 \times 42 \times 50 \mathrm{~cm})$ by using thermoelectric module. Test result found that the ambient temperature $23^{\circ} \mathrm{C}$ and relative humidity about $30 \% \mathrm{RH}$, this refrigerator can make the minimum temperature at $8^{\circ} \mathrm{C}$, for minimum energy consumption can make temperature at $15^{\circ} \mathrm{C}$. Linlin Cao [9] has designed thermoelectric cooling helmet for the person that work under the high temperature environment by using TECs model TEC-12706, the internal temperature of cooling helmet is between $24-30^{\circ} \mathrm{C}$ which in comfort zone of human body. Hayder Al-Madhhachi [10] has been constructed the water distillation system with both sides of thermoelectric module, by pump the water through the hot side of the module. The hot side temperature is about $50^{\circ} \mathrm{C}$ that can make the water evaporate to vapor. When the vapor pass the cool side, it will condense simultaneously. The result found the distillated water production is $28.5 \mathrm{ml} / \mathrm{h}$ with the specific energy consumption of $0.00114 \mathrm{~kW} \mathrm{h/ml} \mathrm{of} \mathrm{the} 10 \times 10 \times 30$ $\mathrm{mm}^{3}$ evaporation chamber.

The recently articles show that thermoelectric module be able to apply the both hot and cool sides of the module to an alternative operation i.e. VCR cycle. Thus, in the heat pump function the thermoelectric module are preferable than VCR because it is smaller size, easier installation, operation and parameter adjusting. Especially it is a solid state device and never needs to use any refrigerants [11]. Therefore, the VCR might be replaced by the thermoelectric module in function of heat pump and air dehumidification of the dryer.

This research objective was to study the performance of the heat generating and heat exchanging with air of the thermoelectric module model TEC- 12710 by testing and investigate the highest air temperature, heat rate in air flow, power consumption, moisture extraction rate and coefficient of performance for the possibility evaluation when it will be modified to use in the agricultural products drying system.

\section{Experimental apparatus and Testing}

\section{Experimental apparatus}

The apparatus was constructed for test the thermoelectric module model TEC-12710. The system was shown in Fig. $3 \mathrm{a}$ that consisted of a square air duct made from acrylic plastic sheet and covered inside wall with insulation sheet. The air fins heat exchangers were installed on the both hot and cool sides of TEC module. The size of air fins heat exchanger on the hot side is larger than air fins of the cool side to discharge the self-heating that caused by heat transfer output is less than the energy input on the module. The ventilation of hot and cool air in duct are independent flow and can vary the air flow rate by each electric fan. A dry bulb temperature and relative humidity of air at position 1,2 and 3 in Fig.3a were read by temperature and humidity sensor (ShenZhen model DHT22 FZ0757) that works with microprocessor board Arduino to collect the data from the experiment. The apparatus prototype shown in Fig. $3 \mathrm{~b}$.

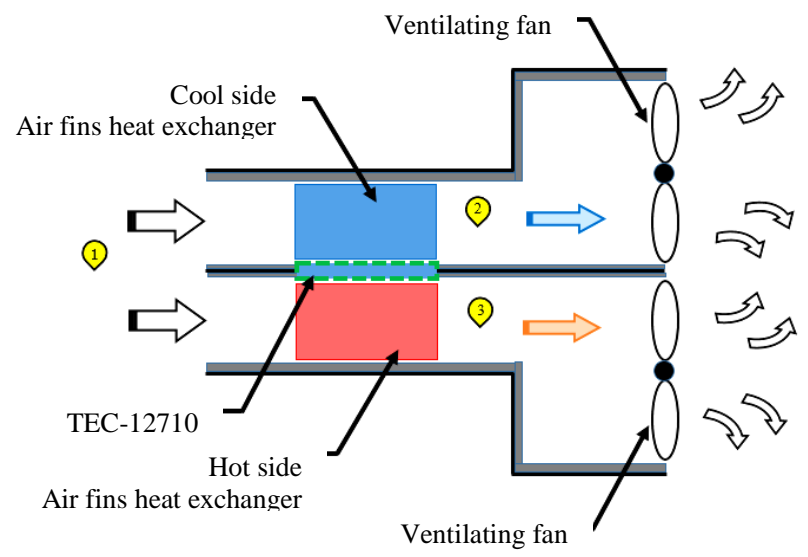

(a)

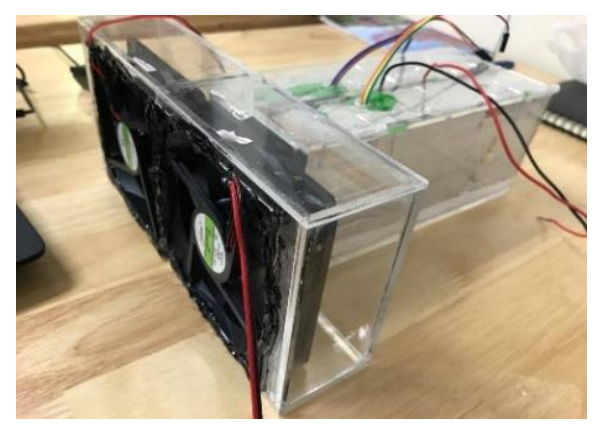

(b)

Figure 3. (a) Diagram and (b) Prototype of apparatus 
Proc. of the Eighth International Conference On Advances in Mechanical, Aeronautical and Production Techniques - MAPT 2018 Copyright (C) Institute of Research Engineers and Doctors. All rights reserved.

ISBN: 978-1-63248-147-4 doi: 10.15224/ 978-1-63248-147-4-23

\section{Testing}

Thermal performance was determined by investigate the properties of air flow through TEC module, the DC Voltage was varied and supplied to the TEC module. A couple of fans at hot and cool sides outlet air duct were independently speed controlled by varying each fan supplied DC Voltage. The Variables and its level in the testing were shown in TABLE I. The maximum DC voltage on TEC-12710 module and fans are $17.4 \mathrm{~V}$ and $12 \mathrm{~V}$ respectively and there were divided into 5 levels in the experiment. Each level of voltage supply to ventilating fan, the air flow rate was measured (Fig. 4) by electronic anemometer (Benetech model GM8901). The tubing for the flow measurement was shown in Fig 4. All treatments were test 3 replications in this experiment.

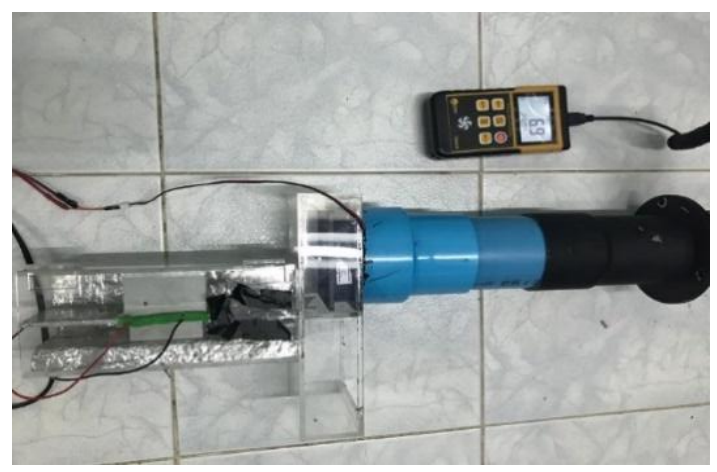

Figure 4. Air measurement while vary the fan voltage supply

The data of air from the experiment used to determine the absolute humidity $(\mathrm{H})$, Enthalpy $(\mathrm{h})$ and density $(\rho)$ by Psychrometric chat [12] for the heat rate of hot side $\left(Q_{h}\right)$ and cool side $\left(\mathrm{Q}_{\mathrm{c}}\right)$ outlet air and the moisture extraction rate (MER) calculation by (1), (2) and (3) respectively.

TABLE I. VARIABLES IN EXPERIMENT

\begin{tabular}{|l|r|r|r|r|r|}
\hline \multicolumn{5}{|c|}{ Variables and its level in experiment } \\
\hline \multicolumn{1}{|c|}{ Variables } & Level 1 & Level 2 & Level 3 & Level 4 & Level 5 \\
\hline $\begin{array}{l}\text {-Voltage input for } \\
\text { TEC (V) }\end{array}$ & 3 & 6 & 9 & 12 & 16 \\
\hline $\begin{array}{l}\text {-Voltage input for } \\
\text { hot side fan (V) } \\
\text {-Air flow rate of hot } \\
\text { side (kg dry air/s) }\end{array}$ & 0.0106 & 0.0144 & 0.0164 & 0.0202 & 0.0229 \\
\hline $\begin{array}{l}\text {-Voltage input for } \\
\text { cool side fan (V) } \\
\text {-Air flow rate of } \\
\text { cool side (kg dry air } / \mathrm{s})\end{array}$ & 0.0068 & 0.0089 & 0.0103 & 0.0130 & 0.0151 \\
\hline
\end{tabular}

\section{Equations}

The calculation of heat rate of outlet air on hot and cool side use equations by Cengel [13]. The heat rate of air flow through the hot side of module as in (1).

$$
\mathrm{Q}_{\mathrm{h}}=\mathrm{n}_{\mathrm{hot}}\left(\mathrm{h}_{3}-\mathrm{h}_{1}\right)
$$

For the heat rate of air flow through the cool side of module as in (2).

$$
\mathrm{Q}_{\mathrm{c}}=\mathrm{nd}_{\mathrm{col}}^{\mathrm{k}}\left(\mathrm{h}_{1}-\mathrm{h}_{2}\right)
$$

Where $\mathrm{Q}_{\mathrm{h}}$ is the heat rate of the hot side of module $(\mathrm{kW})$
$\mathrm{Q}_{\mathrm{c}}$ is the heat rate at the cool side of module $(\mathrm{kW})$

$\mathrm{n} \&$ is the air flow rate $(\mathrm{kg} / \mathrm{s})$ for the hot and cool side

$\mathrm{h}$ is enthalpy $(\mathrm{kJ} / \mathrm{kg})$; subscript 1 is inlet, 2 is hot side outlet and 3 is cool side outlet

The moisture extraction rate (MER) was calculated by (3) that applied from Amalendu [14].

$$
\operatorname{MER}=\mathrm{nd}_{\mathrm{cool}}^{\&}\left(\mathrm{H}_{1}-\mathrm{H}_{2}\right)
$$

Where MER is moisture extraction rate $\left(\mathrm{kg}_{\text {water }} / \mathrm{s}\right)$

$\mathrm{H}$ is absolute humidity $\left(\mathrm{kg}_{\text {water }} / \mathrm{kg}_{\text {dry air }}\right)$; subscript 3 is cool side outlet and 1 is inlet

For the coefficient of performance (COP) of the cooling ability of module, Stoecker [15] equation was selected as in (4).

$$
\mathrm{COP}=\frac{\mathrm{Q}_{\mathrm{c}}}{\text { Watt of thermoelectric }}=\frac{\mathrm{Q}_{\mathrm{c}}}{\mathrm{IxV}}
$$

Where $\mathrm{I}$ is current input to module (Amp.)

$\mathrm{V}$ is voltage input to module (Volt)

\section{Results and discussion}

Maximum hot side outlet air temperature: From the various test, the results found that if the voltage input to TEC module is increasing the module has more ability to produce the large heat too. The temperature of hot side outlet air while power input to TEC module is $16 \mathrm{~V}$ and 8.5 $\mathrm{A}$ is shown in Fig. 5

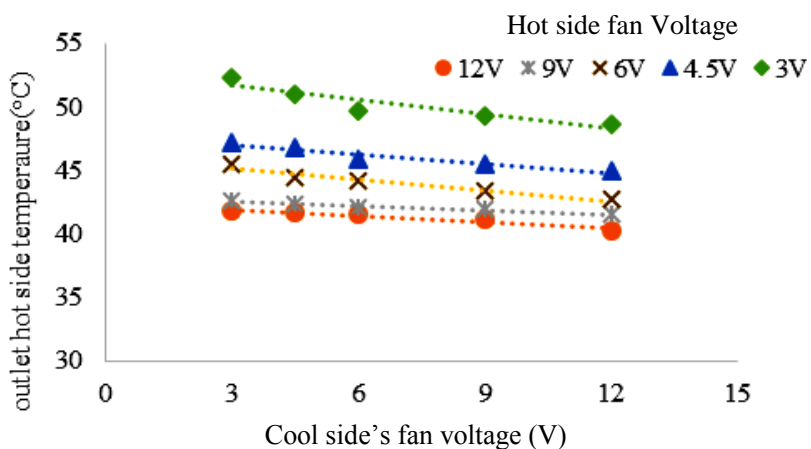

Figure 5. The hot side outlet air temperature while TEC power input is $16 \mathrm{~V} 8.5 \mathrm{~A}$

At the high voltage supplied to TEC module, the lower air flow rate of the hot side and cool side that were affect by the low level of voltage supplied to the electric fan are inversely change with the rising of hot air temperature on the hot side outlet air. Because at lower air flow rate the air speed is very low. Then, it has enough a time for the hot side air to receive the heat flux from TEC module while the cool side air transfer its heat to the TEC module in the same time.

Maximum heat rate of hot side outlet air $\left(Q_{h}\right)$ : In Fig. $6 \mathrm{a}$, the supplying of $16 \mathrm{~V}$ to the TEC module gives the maximum $\mathrm{Q}_{\mathrm{h}}$ (shown by the left vertical axis of graph) at $0.448 \mathrm{~kW}$ with the electric power input of $16 \mathrm{~V} 8.5 \mathrm{~A}$ when we use the lowest air flow rate of the cool outlet air side with the middle air flow rate of the hot side outlet air together. The heat rate of cool side outlet air $\left(Q_{c}\right)$ shown in minus value (on the right vertical axis of graph) because 
Proc. of the Eighth International Conference On Advances in Mechanical, Aeronautical and Production Techniques - MAPT 2018 Copyright (C) Institute of Research Engineers and Doctors. All rights reserved.

ISBN: 978-1-63248-147-4 doi: 10.15224/ 978-1-63248-147-4-23

under the maximum module voltage supplied, the electric fan in this experiment cannot relief the heat generated on the module rapidly enough. Finally, the self-heating effect is occurring on the module and effects a cool side outlet air temperature higher than the inlet.

Maximum heat rate of cool side outlet air $\left(Q_{c}\right)$ : In Fig. $6 \mathrm{~b}$, when we desire to avoid the self-heating effect on the TEC module by supplying the low voltage to the module. The highest $\mathrm{Q}_{\mathrm{c}}$ that TEC module can received from the air is $0.025 \mathrm{~kW}$ with the electric power input to the module $6 \mathrm{~V}$ 3.5 A similarly in any fan flow rate. By the way, supplying the low voltage to module also effects on the low value of $\mathrm{Q}_{\mathrm{h}}$ too.

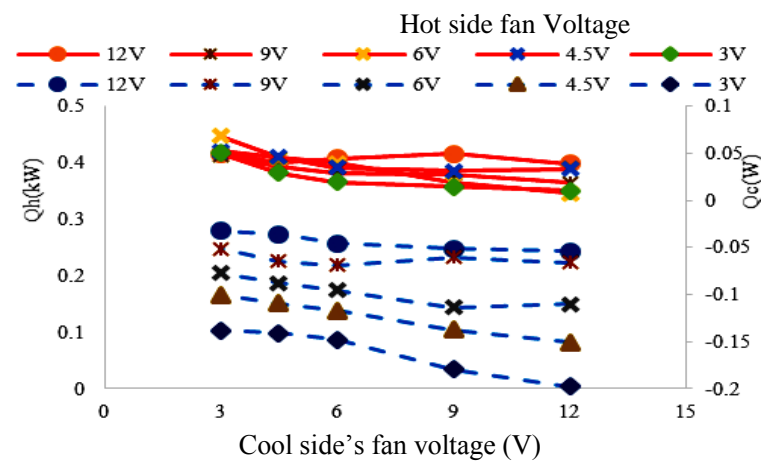

(a)

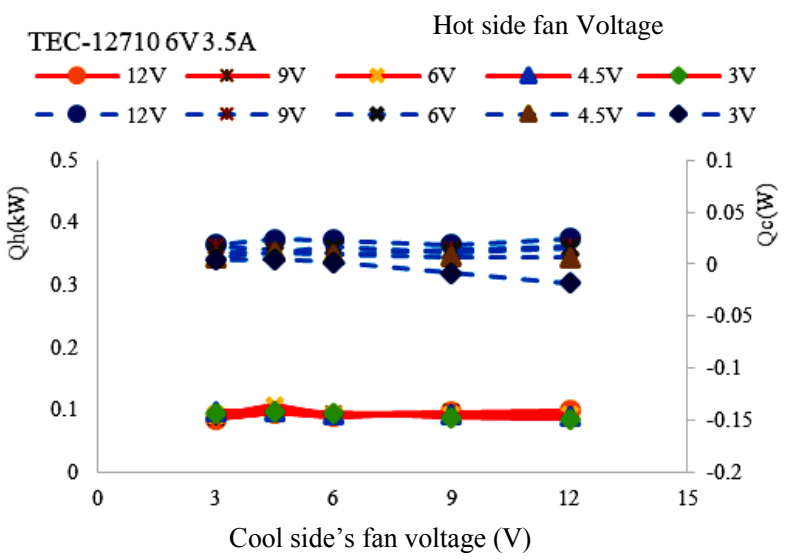

(b)

Figure 6. The heat rate of hot and cool side outlet air (a) when TEC's $16 \mathrm{~V} 8.5 \mathrm{~A}$ power input (b) when TEC's $6 \mathrm{~V} 3.5 \mathrm{~A}$ power input

From the results, the maximum values of $\mathrm{Q}_{\mathrm{h}}$ and $\mathrm{Q}_{\mathrm{c}}$ never occur at the same experiment condition. Therefore, the applying of TEC module with the heat pump dryer should separately use the TEC module into two sets of module and separate the power supply and its controller for use one set of module as the heater (replace with the condenser unit in VCR) and another set as the moisture extractor (replace with the evaporator unit in VCR).

Moisture extraction rate (MER): Shown in Fig. 7 . The highest of MER is $0.016 \mathrm{~kg}_{\text {water }} / \mathrm{h}$ at hot side air flow rate $0.0229 \mathrm{~kg}$ dry air $/ \mathrm{s}$ and cool side air flow rate $0.0089 \mathrm{~kg}$ dry air $/ \mathrm{s}$ when the TEC module was powered by $6 \mathrm{~V}$ and $3.5 \mathrm{~A}$. But some experiment cannot calculate the MER because the selfheating effect is occurred on the hot side of TEC module due to the experiment. It makes the cool side of TEC cannot extract the moisture from the air, so the outlet absolute humidity is equal or maybe higher than the inlet.

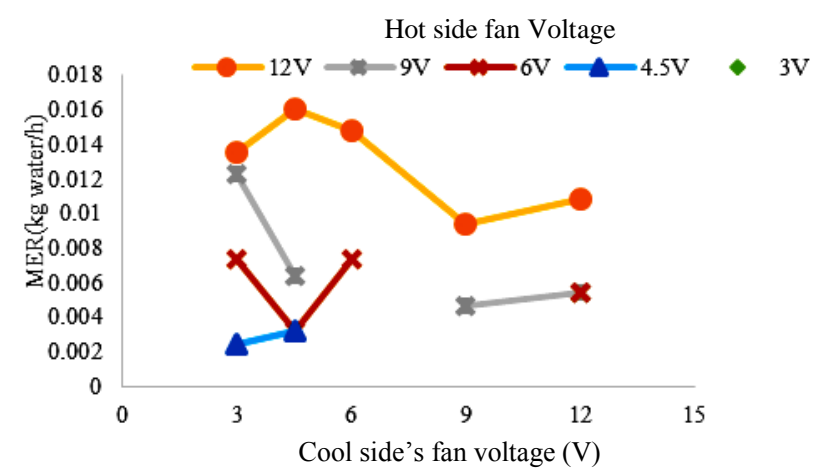

Figure 7. The MER on experiment while TEC's 6V 3.5A power input

Coefficient of Performance (COP): The interested COP of the cool side of TEC module is the worthy use in moisture extraction process. It shows in Fig. 8.

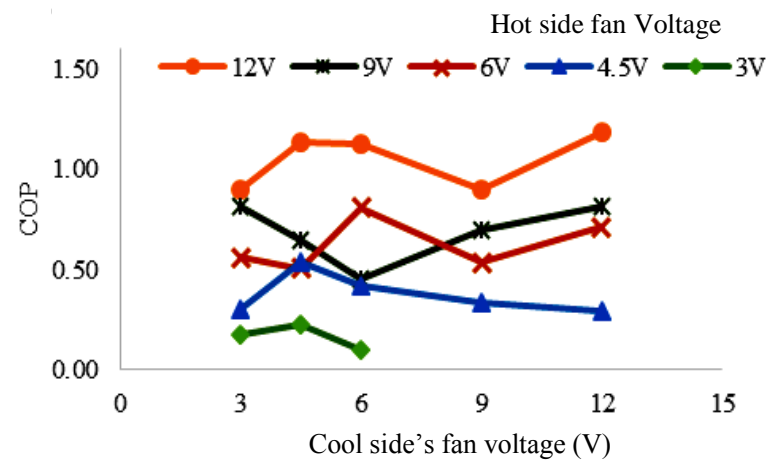

Figure 8. COP of cool side on TEC module while TEC's 16V 8.5A power input

From the results, the highest COP is 1.14 when the TEC module was supplied by $6 \mathrm{~V} 3.5 \mathrm{~A}$ and the air flow rate of cool side and hot side is low. Because at the low air speed the time is longer than higher air speed and the moist air can easy exchange the heat to the cool side of TEC module. After that, the air will be cool until closely to the point of dew temperature, so the moist in air will condense to the water and extract out from the air in finally.

All the appropriate parameter results were shown in the TABLE II.

TABLE II. THE RESULTS OF EXPERIMENT

\begin{tabular}{|l|c|c|c|c|}
\hline \multicolumn{1}{|c|}{ Parameters } & $\begin{array}{c}\text { Best } \\
\text { result }\end{array}$ & $\begin{array}{c}\text { TEC } \\
\text { supply }\end{array}$ & $\begin{array}{c}\text { Hot side air } \\
\text { flow (kg/s) }\end{array}$ & $\begin{array}{c}\text { Cool side air } \\
\text { flow (kg/s) }\end{array}$ \\
\hline Hot air Temp. $\left({ }^{\circ} \mathrm{C}\right)$ & $52.3^{\mathrm{a}}$ & $16 \mathrm{~V}, 8.5 \mathrm{~A}$ & 0.0106 & 0.0068 \\
\hline $\mathrm{Q}_{\mathrm{h}}(\mathrm{kW})$ & $0.448^{\mathrm{a}}$ & $16 \mathrm{~V}, 8.5 \mathrm{~A}$ & 0.0165 & 0.0068 \\
\hline $\mathrm{Q}_{\mathrm{c}}(\mathrm{kW})$ & $0.025^{\mathrm{a}}$ & $6 \mathrm{~V}, 3.5 \mathrm{~A}$ & 0.0229 & 0.0151 \\
\hline $\mathrm{MER}\left(\mathrm{kg}_{\mathrm{water}} / \mathrm{h}\right)$ & $0.016^{\mathrm{a}}$ & $6 \mathrm{~V}, 3.5 \mathrm{~A}$ & 0.0229 & 0.0089 \\
\hline $\mathrm{COP}$ & $1.14^{\mathrm{a}}$ & $6 \mathrm{~V}, 3.5 \mathrm{~A}$ & 0.0229 & 0.0151 \\
\hline
\end{tabular}

\section{Conclusions}

Study of thermal performance of the thermoelectric module model TEC-12710. The results found that the supplying of $16 \mathrm{~V}, 8.5 \mathrm{~A}$ DC electricity to the module gains 
Proc. of the Eighth International Conference On Advances in Mechanical, Aeronautical and Production Techniques - MAPT 2018 Copyright (C) Institute of Research Engineers and Doctors. All rights reserved. ISBN: 978-1-63248-147-4 doi: 10.15224/ 978-1-63248-147-4-23

the air temperature from $30^{\circ} \mathrm{C} 68 \% \mathrm{RH}$ to $52.3^{\circ} \mathrm{C} 26.8 \% \mathrm{RH}$ on the hot side of the module. The system consumes a $40 \mathrm{~W}$ of power and gives the highest moisture extraction rate (MER) at $0.016 \mathrm{~kg}_{\text {water }} / \mathrm{h}$ on the cold side of module by supplying of $6 \mathrm{~V} 3.5 \mathrm{~A}$ and it have the coefficient of performance (COP) at 1.14. It is possible to adapt this module with the drying system especially the heat pump drying system. The application of TEC module with the heat pump dryer should separately use the TEC module into two sets of module and separate the power supply and its controller for use one set of module as the heater (replacing the condenser unit in VCR) and another set as the moisture extractor (replacing the evaporator unit in VCR).

\section{Acknowledgment}

The authors wish to acknowledge the Bio-System Engineering and Technology Laboratory, Suranaree University of Technology for the research support.

\section{References}

[1] Suzanne Driessen, "Food Safety: Drying," Available at: URL:http://www.extension.umn.edu/. Accessed December 24, 2017.

[2] Vivek Tomar, G.N. Tiwari and Brian Norton, "Solar dryers for tropical food preservation: Thermophysics of crops, systems and components," Elsevier, Solar Energy, vol. 154, pp.2-13, May 2017.

[3] Thomas Kivevele and Zhongjie Huan, "A review on opportunities for the development of heat pump drying systems in South Africa," Academy of Science of South Africa, South African Journal of Science, vol. 110, November 2013.

[4] M. Fatouh, M.N. Metwally, A.B. Helali and M.H. Shedid, "Herbs drying using a heat pump dryer," Elsevier, Energy Conversion and Management, vol. 47, pp.2629-2643, October 2005.

[5] Qi-Long Shi, Chang-Hu Xue, Ya Zhao, Zhao-Jie Li and Xiang-You Wang, "Drying characteristics of horse mackerel (Trachurus japonicus) dried in heat pump dehumidifier," Elsevier, Journal of Food Engineering, vol. 84, pp. 12-20, April 2007.

[6] Wei He, Gan Zhang, Xingxing Zhang, Jie Ji, Guiqiang Li and Xudong Zhao, "Recent development and application of thermoelectric generator and cooler," Elsevier, Applied Energy, vol. 143, pp.1-25, December 2014.

[7] Ashok Kumar Yadav, Shatrughan Singh and Gaurav Gupta, "Solar Air-Conditioning: Design for a Compressor-Less System using Peltier Effect," ResearchGate, International Jourlnal of Advance Research and Innovation, vol. 2, pp.429-432, May 2014.

[8] Diana Enescu, Alessandro Ciocia, Andrea Mazza and Angela Russo, "Solutions based on thermoelectric refrigerators in humanitarian contexts," Elsevier, Sustainable Energy Technologies and Assessments, vol. 22, pp.134-149, February 2017.

[9] Linlin Cao, Jitian Han, Lian Duan and Chong Huo, "Design and Experiment Study of a New Thermoelectric Cooling Helmet," Elsevier, Procedia Engineering, vol. 205, pp.1426-1432, October 2017.

[10] Hayder Al-Madhhachi and Gao min, "Effective use of thermal energy at both hot and cold side of thermoelectric module for developing efficient thermoelectric water distillation system," Elsevier, Energy Conversion and Management, vol. 133, pp.14-19, November 2016.

[11] S. Manikandan, S.C. Kaushik and Ronggui Yang, "Modified pulse operation of thermoelectric coolers for building cooling applications," Elsevier, Energy Conversion and Management, vol. 140, pp.145-156, March 2017.

[12] American society of heating, 2009 ASHRAE handbook: fundamentals, Atlanta:GA, 2009.

[13] Yunus A. Cengel, Thermodynamics An Engieer Approach, $5^{\text {th }}$ edition, New York city: McGraw-Hill Science, 2004.

[14] Amlendu Chakraverty and R. Paul Singh, Postharvest Technology, Enfield: Science Publishers, 2001.
[15] W. F. Stoeker and J. W. Jones, Refrigeration and Air Conditioning, $2^{\text {nd }}$ edition, New York city: McGraw-Hill International Edition, 1982.

About Author :

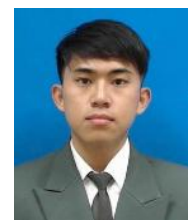

Patchara Wongpaisarnkit, B. ( $1^{\text {st }}$ Hons $)$ Eng. (Mechanical Engineering) Suranaree University of Technology (Thailand). Currently he is a graduate Student in a Program of Mechanical Engineering and process system, Suranaree University of Technology.

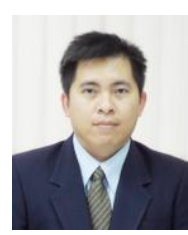

Krawee Treeamnuk, D. Eng. He is currently an Assistant Professor at School of Mechanical Engineering, Institute of Engineering, Suranaree University of Technology (Thailand). His research interest are mainly in the area of postharvest machines and process, nondestructive technique, thermal process in agricultural system.

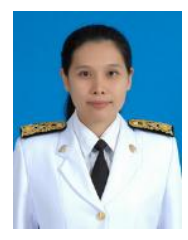

Tawarat Treeamnuk, D. Eng. She is currently an Assistant Professor at School of Agricultural engineering, Institute of Engineering, Suranaree University of Technology (Thailand). Her areas of research interests are food processing, post-harvest technology, drying. 